Article

\title{
Genotype and Phenotype Analyses in Pediatric Patients with HNF1B Mutations
}

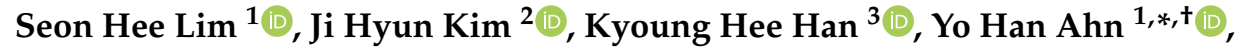 \\ Hee Gyung Kang ${ }^{1}$ (D), Il-Soo Ha ${ }^{1}$ and Hae Il Cheong ${ }^{1, *,+}$ \\ 1 Department of Pediatrics, Seoul National University Children's Hospital, Seoul 03080, Korea; \\ kkrsh@naver.com (S.H.L.); kanghg@snu.ac.kr (H.G.K.); ilsooha@snu.ac.kr (I.-S.H.) \\ 2 Department of Pediatrics, Seoul National University Bundang Hospital, Seongnam 13620, Korea; \\ pedkimji@gmail.com \\ 3 Department of Pediatrics, Jeju National University School of Medicine, Jeju 63243, Korea; \\ hansyang78@gmail.com \\ * Correspondence: yhahn@snuh.org (Y.H.A.); cheonghi@snu.ac.kr (H.I.C.) \\ + These authors equally contributed to this work.
}

Received: 27 June 2020; Accepted: 17 July 2020; Published: 21 July 2020

\begin{abstract}
HNF1B mutations, one of the most common causes of congenital anomalies of the kidney and urinary tract, manifest as various renal and extrarenal phenotypes. We analyzed the genotype-phenotype correlations in 14 pediatric patients with HNF1B mutations. Genetic studies revealed total gene deletion in six patients $(43 \%)$. All patients had bilateral renal abnormalities, primarily multiple renal cysts. Twelve patients exhibited progressive renal functional deterioration, and six of them progressed to kidney failure. The annual reduction in estimated glomerular filtration rate was $-2.1 \mathrm{~mL} / \mathrm{min} / 1.73 \mathrm{~m}^{2}$. Diabetes developed in five patients $(36 \%)$, including one patient with new-onset diabetes after transplantation. Neurological deficits were noted in three patients $(21 \%)$, one with total gene deletion and two with missense mutations. Pancreatic abnormalities were more frequent in patients with missense mutations than in patients with other types of mutations. Genotype showed no significant correlation with renal outcomes or other extrarenal manifestations. The HNF1B scores at the times of onset and genetic diagnosis were $<8$ in two patients and one patient, respectively. Diagnosis of HNF1B mutations is clinically difficult because of extreme phenotypic variability and incomplete penetrance. Furthermore, some phenotypes develop with age. Therefore, patient age should be taken into consideration to increase the diagnostic rate, because some phenotypes develop with age.
\end{abstract}

Keywords: hepatocyte nuclear factor 1- $\beta$; HNF1B; congenital anomalies of the kidney and urinary tract; renal cysts and diabetes syndrome; chronic kidney disease

\section{Introduction}

Hepatocyte nuclear factor-1-beta (HNF1 $\beta$ ), also known as transcription factor-2 (TCF2), is a member of the homeodomain-containing superfamily of transcription factors [1]. During the embryonic period, early expression of HNF1 $\beta$ is seen in the kidneys, liver, pancreas, bile ducts, urogenital tract, lungs, thymus, and gut, where it plays an important role in the normal development of these organs [2]. Accordingly, heterozygous mutations in HNF1B result in a variety of phenotypes involving multiple organs [2-4].

The kidneys are the most commonly affected organs, and renal manifestations encompass a wide spectrum of congenital abnormalities of the kidney and urinary tract (CAKUT) [3-5]. HNF1B mutations are the most common monogenetic cause of CAKUT and are found in $5-38 \%$ of the patients depending 
on the screening policy and study design [3,5-9]. Cystic kidney disease, including cystic dysplasia, is the predominant form of CAKUT associated with HNF1B mutations [5]. Electrolyte imbalances, such as hypomagnesemia, hypokalemia, and hyperuricemia, are also a common feature of HNF1B mutations $[3,10,11]$.

Almost all patients with $H N F 1 B$ mutations have renal manifestations either isolated or in combination with extrarenal manifestations [5,6]. Maturity-onset diabetes of the young type 5 (MODY5) is one of the well-known extrarenal manifestations of HNF1B mutations, and the combined phenotypes of renal cysts and diabetes are referred to as RCAD syndrome [12]. Other extrarenal phenotypes include pancreatic hypoplasia with exocrine pancreatic dysfunction, genital tract malformations, abnormal liver function, and neurological disorders [3-5,10]. Renal and extrarenal phenotypes of HNF1B mutations show not only a wide spectrum but also high heterogeneity, even among individuals with the same inherited mutation $[5,13,14]$. No clear genotype-phenotype correlations have been demonstrated thus far.

In this study, we analyzed the renal and extrarenal manifestations as well as genotype-phenotype correlations in pediatric patients with HNF1B mutations.

\section{Methods}

\subsection{Subjects}

A total of 14 unrelated Korean patients with HNF1B mutations who were diagnosed at the Department of Pediatrics, Seoul National University Children's Hospital, Seoul, Korea from 2008 to 2019 were recruited in this study. These patients were identified by genetic screening of HNF1B gene mutations in 110 patients with CAKUT with bilateral renal involvement. The phenotypes of the patients were analyzed by a retrospective review of medical records, and the HNF1B score proposed by Faguer et al. Ref. [15] was calculated for each patient. Hypokalemia and hypomagnesemia were defined as serum potassium level $<3.5 \mathrm{mmol} / \mathrm{L}$ and serum magnesium level $<1.4 \mathrm{mEq} / \mathrm{L}$, respectively [13]. Hyperuricemia was defined as serum uric acid above $7.0 \mathrm{mg} / \mathrm{dL}$ [7]. Electrolytes abnormalities were diagnosed when abnormal levels were found repeatedly or treatment was necessary. With respect to the evaluation of renal function, the estimated glomerular filtration rate (eGFR) was calculated using the Schwartz equation [16] for patients $<20$ years of age and using the Chronic Kidney Disease Epidemiology Collaboration (CKD-EPI) [17] for those who were $\geq 20$ years of age.

This study was approved by the Institutional Review Board of Seoul National University Hospital (IRB No. 0812-002-264). Informed consent was obtained from all individual participants and/or their parents.

\subsection{Genetic Analysis}

Genetic studies included Sanger sequencing, targeted exome sequencing, whole exome sequencing, and multiplex ligation-dependent probe amplification (MLPA). All coding exons with flanking introns of the HNF1B gene were amplified using polymerase chain reaction (PCR) followed by Sanger sequencing. PCR primer sequences are provided in Table S1. Targeted exome sequencing was designed to capture 60 genes that have been reported to cause CAKUT in humans or murine models. The detailed procedures of targeted exome sequencing, whole exome sequencing, and bioinformatic analyses have been described previously $[18,19]$. MLPA analysis was performed to determine the presence of copy number variations using a commercial kit (SALSA ${ }^{\circledR}$ MLPA ${ }^{\circledR}$ P241-E1 Probemix; MRC-Holland, Amsterdam, The Netherlands).

\subsection{Statistical Analysis}

The distribution of continuous variables is indicated by the median with range. The Mann-Whitney test was used to compare the sizes of two independent groups, and the Kruskal-Wallis test was used to compare the sizes of three groups. The Freeman-Halton extension of Fisher exact test was utilized 
to test for the difference in distribution of categorical variables between three groups. Kaplan-Meier survival curves were employed to compare the renal survival using end-stage renal disease (ESRD) as an end point. All values are expressed as the median with interquartile range (IQR). A $p$ value $<0.05$ was considered to be statistically significant. IBM SPSS Statistics 20 software (IBM Co., Armonk, NY, USA) was used for all calculation.

\section{Results}

\subsection{Baseline Characteristics}

All patients were male except for Patient 1 . The median ages at the times of onset and genetic diagnosis were 0.1 years (IQR 0.0-9.3) and 12.9 years (IQR 10.1-17.1), respectively. The median age at the last follow-up was 19.8 years (IQR 13.6-23.1), and the median duration of follow-up was 13.6 years (IQR 8.4-19.3). Five patients (36\%) presented abnormal findings in prenatal ultrasonography, and another five patients displayed incidental azotemia with or without recurrent urinary tract infections. Analysis of family history revealed diabetes mellitus in seven patients (50\%) and cystic kidney disease in three patients (21\%; Table 1$)$. 
Table 1. Genotypes and renal phenotypes of the patients.

\begin{tabular}{|c|c|c|c|c|c|c|c|}
\hline \multirow{2}{*}{$\mathbf{P t}$} & \multicolumn{2}{|c|}{ Age (Year) at } & \multirow{2}{*}{ Mode of Onset } & \multirow{2}{*}{ Family History } & \multirow{2}{*}{ Mutations (REFSEQ: NM_000458.3) } & \multirow{2}{*}{ Kidney Imaging } & \multirow{2}{*}{ Latest eGFR } \\
\hline & Onset & Dx & & & & & \\
\hline 1 & 0.0 & 14.1 & Abnormal prenatal USG & DM & c. $443 \mathrm{C}>\mathrm{T}(\mathrm{p} . \mathrm{S} 148 \mathrm{~L})$ & Нypo (B), HE (B) & $113^{\mathrm{b}}$ \\
\hline 2 & 11.1 & 13.1 & DM & No & c.503T > C (p.L168P) & Cyst (B), HE (B) & 36 \\
\hline 3 & 0.0 & 11.6 & Incidental renal cysts & DM, Cyst & Total deletion & Cyst (B), HN (B) & 105 \\
\hline 4 & 0.0 & 12.0 & Abnormal prenatal USG & No & Total deletion & Cyst (B) & 80 \\
\hline 5 & 0.1 & 16.7 & Incidental azotemia & $\mathrm{DM}$ & Total deletion & Cyst (R), HE (R), MCDK (L), HN (R) & $69^{b}$ \\
\hline 6 & 0.0 & 0.2 & Incidental azotemia & DM & c.541C > T (p.R181*) & Cyst (L), MCDK (B) & $69^{b}$ \\
\hline 7 & 7.1 & 8.6 & Recurrent UTI & No & c. $439 C>$ G (p.Q147E) ${ }^{a}$ & Cyst (B), HE (B) & 9 \\
\hline 8 & 8.9 & 19.6 & Incidental proteinuria & No & c. $313 \mathrm{G}>\mathrm{A}(\mathrm{p} . \mathrm{E} 105 \mathrm{~K})^{\mathrm{a}}$ & Cyst (R), VUR (L) & $40^{b}$ \\
\hline 9 & 0.0 & 2.7 & Abnormal prenatal USG & $\mathrm{DM}$ & c.1103_1116del14 (p.H368Rfs*27) ${ }^{a}$ & Cyst (R), HE (R), MCDK (L) & 53 \\
\hline 10 & 0.0 & 12.6 & Abnormal prenatal USG & No & Total deletion & Cyst (R), HE (R), MCDK (L), HN (R) & 31 \\
\hline 11 & 0.2 & 18.3 & Azotemia with recurrent UTI & No & Total deletion & HE (B), VUR (B) & $105^{\mathrm{b}}$ \\
\hline 12 & 0.1 & 15.6 & Abnormal prenatal USG & $\mathrm{DM}$ & Total deletion & Cyst (B), HE (B) & 124 \\
\hline 13 & 20.9 & 21.4 & Incidental azotemia & Cyst & c.454delC (p.Q152fs*9) a & Cyst (B) & 64 \\
\hline 14 & 10.5 & 10.6 & Incidental azotemia & DM, Cyst & c. $1235 \mathrm{delC}(\mathrm{p} \cdot \mathrm{P} 412 \mathrm{Qfs} * 5)^{\mathrm{a}}$ & Cyst (B), HE (B) & 44 \\
\hline
\end{tabular}

a Novel mutations. ${ }^{\mathrm{b}}$ Patients who received renal transplantation. Pt, patient; Dx, diagnosis; eGFR, estimated glomerular filtration rate (mL/min/1.73 $\left.\mathrm{m}^{2}\right)$; USG, ultrasonography; DM, diabetes mellitus; UTI, urinary tract infection; Cyst, multiple renal cysts; Hypo, renal hypoplasia; HE, renal parenchymal hyperechogenicity; HN, hydronephrosis; MCDK, multicystic dysplastic kidney; B, bilateral; L, left; R, right; VUR, vesicoureteral reflux. 


\subsection{HNF1B Genotypes}

HNF1B analyses revealed nine different mutations, including four missense mutations, three frame-shift short deletion mutations, one nonsense mutation, and total deletion. Five of the mutations were novel classified as "likely pathogenic" variants according to the 2015 American College of Medical Genetics and Genomics-Association for Molecular Pathology (ACMG-AMP) guidelines [20]. All mutations were unique to individual patients except for the total deletion, which was detected in six patients (43\%; Table 1$)$.

\subsection{Renal Phenotypes}

All patients exhibited abnormal findings on renal ultrasonographic examination; multiple renal cysts were observed in 12 patients $(86 \%)$, renal parenchymal hyperechogenicity was observed in nine patients $(64 \%)$, unilateral multicystic dysplastic kidney was observed in four patients $(29 \%)$, hydronephrosis was observed in three patients $(21 \%)$, and vesicoureteral reflux was observed in two patients $(14 \%)$.

At the last follow-up, 12 patients (86\%) showed progressive renal functional deterioration (eGFR $<90 \mathrm{~mL} / \mathrm{min} / 1.73 \mathrm{~m}^{2}$ ), including six patients (43\%) who progressed to ESRD at the median age of 10.7 years (IQR 5.6-15.3; Table 1). One of the patients (Patient 6) manifested ESRD during the neonatal period. The annual reduction in eGFR, which was calculated in 13 patients using serial eGFR values measured after 2 years of age, was $-2.1 \mathrm{~mL} / \mathrm{min} / 1.73 \mathrm{~m}^{2}$ (IQR $-4.2--1.0 \mathrm{~mL} / \mathrm{min} / 1.73 \mathrm{~m}^{2}$ ), and the reduction rates showed no significant difference between patients who progressed with ESRD $(-2.1$ [IQR $\left.-4.2--1.4] \mathrm{mL} / \mathrm{min} / 1.73 \mathrm{~m}^{2}\right)$ and those who did not $\left(-2.3[\mathrm{IQR}-4.2--1.2] \mathrm{mL} / \mathrm{min} / 1.73 \mathrm{~m}^{2}\right)$. The kidney survival rates at the 10-year and 20-year follow-up were $79 \%$ and $49 \%$, respectively (Figure 1A).
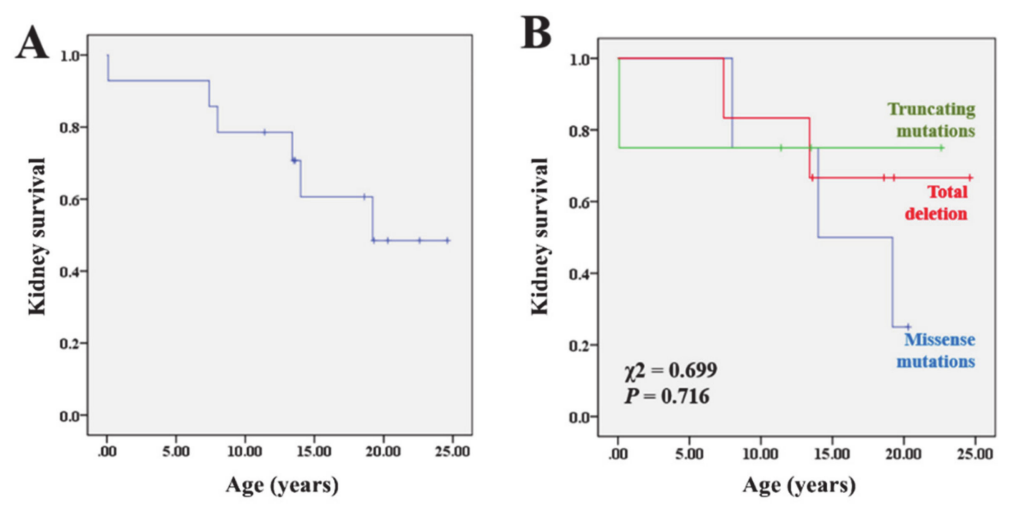

Figure 1. Kaplan-Meier cumulative kidney survival rates in all patients (A) and according to the genotype (B).

\subsection{Extrarenal Phenotypes and Biochemical Data}

Diabetes mellitus was detected in four patients (29\%) (Table 2). The median age at diabetes onset in the four patients with pretransplant diabetes was 14.6 years (IQR: 11.6-16.5). The four patients required oral hypoglycemic agents or insulin therapy to control hyperglycemia. In addition, one patient (Patient 5) developed diabetes after renal transplantation. Four patients had pancreatic abnormalities of hypoplasia or cyst, and two of them developed diabetes during the follow-up. Abnormal liver function tests and abnormalities in the hepatobiliary tract were noted in eight (57\%) and five (36\%) patients, respectively. Hyperparathyroidism was identified in eight patients (57\%). Hypokalemia, hypomagnesemia, and hyperuricemia were observed in seven $(50 \%)$, three $(21 \%)$, and eleven $(79 \%)$ patients, respectively. While two patients with hypomagnesemia needed magnesium supplements for 4 and 15 months, hypokalemia resolved spontaneously in all the cases without potassium replacement. Anti-hyperuricemic agents were prescribed in 8 of 11 patients. 
Table 2. Extrarenal phenotypes of the patients.

\begin{tabular}{|c|c|c|c|c|c|c|c|c|}
\hline $\mathbf{P t}$ & Hypo-Kalemia & Hypo-Magnesemia & Hyper-Uricemia & $\begin{array}{l}\text { DM/Pancreatic } \\
\text { Abnormalities }\end{array}$ & Hyper-Parathyroidism & $\begin{array}{l}\text { Hepatobiliary } \\
\text { Abnormalities }\end{array}$ & Others & HNF1B Score ${ }^{a}$ \\
\hline 1 & $(-)$ & $(-)$ & $(-)$ & $(+) /$ atrophy & $(+)$ & $(-)$ & Mental retardation, ADHD & 30 \\
\hline 2 & $(-)$ & $(-)$ & $(+)$ & $(+) /$ atrophy & $(-)$ & $(-)$ & Polycythemia, obesity & 20 \\
\hline 3 & $(+)$ & $(-)$ & $(+)$ & $(+) /(-)$ & $(-)$ & aLFT & Obesity & 22 \\
\hline 4 & $(+)$ & $(-)$ & $(+)$ & NA & $(-)$ & $(-)$ & & 10 \\
\hline 5 & $(+)$ & $(-)$ & $(+)$ & $(+) /(-)$ & $(+)$ & aLFT & $\begin{array}{l}\text { Mild mental retardation, ADHD, deep vein } \\
\text { thrombosis, neurogenic bladder }\end{array}$ & 22 \\
\hline 6 & $(+)$ & $(-)$ & $(+)$ & NA & $(+)$ & $(-)$ & $\begin{array}{l}\text { Bilateral inguinal hernia, anisometropia, } \\
\text { nystagmus, delayed language development }\end{array}$ & 8 \\
\hline 7 & $(-)$ & $(+)$ & $(+)$ & $(-) /$ atrophy & $(+)$ & $\begin{array}{l}\text { aLFT, hepatic } \\
\text { cysts }\end{array}$ & $\begin{array}{l}\text { PDA, iliac wing brown tumor, post } \\
\text { urethral dilatation }\end{array}$ & 18 \\
\hline 8 & $(-)$ & $(-)$ & $(+)$ & NA & $(+)$ & aLFT & Obesity & 5 \\
\hline 9 & $(-)$ & $(+)$ & $(-)$ & $(-) /$ tail cyst & $(+)$ & aLFT & & 14 \\
\hline 10 & $(+)$ & $(-)$ & $(+)$ & $(-) /(-)$ & $(+)$ & $\begin{array}{c}\text { aLFT, CBD } \\
\text { stone, } \\
\text { choledochal cyst }\end{array}$ & $\begin{array}{l}\text { Hypospadias, imperforated anus, } \\
\text { urethral obstruction }\end{array}$ & 24 \\
\hline 11 & $(+)$ & $(-)$ & $(+)$ & NA & $(+)$ & $\begin{array}{c}\text { aLFT, } \\
\text { choledochal cyst }\end{array}$ & & 8 \\
\hline 12 & $(-)$ & $(-)$ & $(-)$ & $(+) /(-)$ & $(-)$ & $(-)$ & & 18 \\
\hline 13 & $(+)$ & $(-)$ & $(+)$ & $(-) /(-)$ & $(-)$ & aLFT, GB stone & Obesity, polycythemia & 10 \\
\hline 14 & $(-)$ & $(+)$ & $(+)$ & NA & $(-)$ & $(-)$ & Pectus excavatum & 18 \\
\hline
\end{tabular}

a Calculated at the time of genetic diagnosis. Clinical phenotypes are presented as either present (+) or absent (-). Pt, patient; DM, diabetes
CBD, common bile duct; GB, gallbladder; NA, not available; ADHD, attention deficit hyperactivity disorder; PDA, patent ductus arteriosus. 
Neurological deficits were noted in three patients (21\%); mental retardation with attention deficit hyperactivity disorder was observed in two patients (14\%) and delayed language development was observed in one patient (7\%; Table 2).

\subsection{HNF1B Scores}

The HNF1B score calculated at the time of genetic diagnosis was $\geq 8$ in 13 patients (93\%) with a median value of 18 (IQR 9.5-22). Meanwhile, the HNF1B score at onset was $\geq 8$ in 12 patients (86\%) with a median value of 14 (IQR 9.5-16.5). The median duration between onset and genetic diagnosis was 11.1 years (IQR 1.3-14.3).

\subsection{Genotype-Phenotype Correlations}

The patients were divided into the following three subgroups based on the genotype: patients with total deletion (TD group; $\mathrm{n}=6$ ), patients with missense mutations (MM group; $\mathrm{n}=4$ ), and patients with truncating mutations (TM group; $\mathrm{n}=4$ ). Hypokalemia was not observed in the MM group, while it was detected in $83 \%$ and $50 \%$ of the patients in the TD and TM groups, respectively $(p=0.058)$ (Table 3). Pancreatic abnormalities were identified more frequently in the MM group (75\%) than in the $\mathrm{TM}(25 \%)$ or TD $(0 \%)$ groups $(p=0.049)$. Other phenotypes, HNF1B scores, and renal survival rates showed no significant differences among the three groups (Table 3 and Figure 1B).

Table 3. Comparison of the phenotypes according to the genotypes.

\begin{tabular}{ccccc}
\hline & \multicolumn{3}{c}{ HNF1B Genotypes } & \multirow{2}{*}{$p$ Value } \\
\cline { 2 - 4 } & Missense (n = 4) & Truncating (n= 4) & Total Deletion (n= 6) & \\
\hline Age at onset, years & $8.0(1.8-10.6)$ & $5.3(0.0-18.3)$ & $0.05(0.0-0.13)$ & 0.341 \\
Age at diagnosis, years & $13.1(8.6-13.1)$ & $10.6(1.5-21.4)$ & $14.1(11.9-17.1)$ & 0.443 \\
Age at the last follow-up, years & $20.3(19.0-24.9)$ & $12.5(9.2-20.3)$ & $20.0(17.4-25.8)$ & 0.183 \\
No. of patients with & & & & 0.058 \\
Hypokalemia & 0 & $2(50)$ & $5(83)$ & 0.209 \\
Hypomagnesemia & $1(25)$ & $2(50)$ & 0 & 1.000 \\
Hyperuricemia & $3(75)$ & $3(75)$ & $5(83)$ & 0.473 \\
Diabetes mellitus & $2(50)$ & 0 & $2(33)$ & 0.049 \\
Pancreatic abnormalities & $3(75)$ & $1(25)$ & 0 & 1.000 \\
Hepatobiliary abnormalities & $2(50)$ & $2(50)$ & 1.000 \\
Neurologic abnormalities & $1(25)$ & $1(25)$ & $2(17)$ & 0.500 \\
Progression to ESRD & $3(75)$ & $1(25)$ & $13.5(8.5-15.8)$ & 0.695 \\
HNF1B score [15] at the time of & & & $20(9.5-22.5)$ & 0.437 \\
Onset & $16(4.8-19)$ & $12(8.5-17)$ & $12(8.5-17)$ & \\
Diagnosis & $19(8.5-27.5)$ &
\end{tabular}

Values are expressed as median (interquartile range) and number (\%). ESRD, end-stage renal disease; IQR, interquartile range.

\section{Discussion}

HNF1B is located on chromosome locus 17q12, and the most commonly identified HNF1B mutation in approximately $50 \%$ of patients involves the deletion of entire genes that occurs in the context of a chromosomal microdeletion at 17q12, involving an additional 14 genes [3,21]. In our study, six of the 14 patients $(43 \%)$ had entire gene deletion. Similar to many other studies, all four missense mutations detected in our study were located in the DNA binding domain of the HNF1 $\beta$ protein $[3,5,7,22]$. HNF1B mutations are inherited in an autosomal dominant pattern and equally affect both sexes [23]. The extreme male preponderance in our study cannot be explained and has not been reported in other studies.

The phenotypes of HNF1B mutations are extremely variable with inter- and intrafamilial variability, and patients with $H N F 1 B$ mutations typically present CAKUT, either isolated or in combination with extrarenal manifestations $[5,6,13,14]$. Cystic disease, including cystic dysplasia, is by far the most commonly identified renal phenotype in both pediatric and adult populations in most 
large-scale studies $[7,8,10,24]$, and our study corroborated this finding (bilateral multiple renal cysts in seven patients $(50 \%)$ and unilateral renal cysts with contralateral multicystic dysplastic kidney or vesicoureteral reflux in five patients $(36 \%)$.

Some patients with $H N F 1 B$ mutations present prenatally with typical findings of bilateral hyperechogenic kidneys up on fetal ultrasonography [6]. In our study, five cases were detected based on abnormal findings in prenatal ultrasonography. Electrolyte imbalances, including hypomagnesemia, hyperuricemia, and hypokalemia, are also common in patients with HNF1B mutations, as shown in our study. HNF1B is known to regulate the transcription of FXYD2, which encodes the $\gamma$ subunit of the basolateral $\mathrm{Na}^{+} / \mathrm{K}^{+}$-ATPase and is involved in the reabsorption of magnesium in the distal convoluted tubule [24]. These electrolyte imbalances developed with age and became apparent in late childhood. In addition, abnormal tubular electrolyte handling associated with HNF1B mutations was not restricted to magnesium and potassium, but was rather consistent with a more generalized dysfunction of the distal convoluted tubule indicative of the Gitelman syndrome [11]. It is known that patients with HNF1B mutations usually exhibit a slowly progressive deterioration of renal function throughout adulthood, and it is known that progression to ESRD is rare in childhood [3,4]. While a median yearly decline in the eGFR of $-2.45 \mathrm{~mL} / \mathrm{min} / 1.73 \mathrm{~m}^{2}$ was observed in a study on adult patients [13], another study on pediatric patients [25] revealed a mean annual GFR reduction of $-1.0 \mathrm{~mL} / \mathrm{min} / 1.73 \mathrm{~m}^{2}$. However, a subset of patients develop ESRD at ages $<2$ years. Compared to those in other studies, the patients in our study showed poorer renal functional prognosis; a majority $(86 \%)$ presented a CKD stage $\geq 2$, and half of them had ESRD. The median age of ESRD onset was 10.7 years (IQR: 5.6-15.3) in five patients, and the remaining patient had ESRD during the neonatal period. The annual reduction in eGFR was $-2.1 \mathrm{~mL} / \mathrm{min} / 1.73 \mathrm{~m}^{2}$ (IQR $\left.-4.2--1.0\right)$, and the cumulative kidney survival rates at the 10-year and 20-year follow-up were $79 \%$ and $49 \%$, respectively.

Diabetes mellitus is the most frequent extrarenal phenotype associated with HNF1B mutations. However, diabetes in patients with HNF1B mutations rarely develops in childhood but rather manifests in the third or fourth decades of life [3]. While $24 \%$ of the patients developed diabetes at a mean age of 12 years (range: 10-14) in a UK study [26] on pediatric patients, only 6\% of the patients in a Japanese study [7] developed diabetes in their adolescence. In our study, similar to the UK study, four patients (29\%) developed diabetes at a median age of 14.6 years (IQR 11.6-16.5). In addition, one patient developed diabetes after renal transplantation, i.e., new-onset diabetes after transplant [27]. There was no difference in renal outcomes between patients with diabetes and those without diabetes in our study.

Diagnosis of HNF1B mutations is clinically difficult because of extreme inter- and intrafamilial phenotypic variability, incomplete penetrance, a 50-60\% de novo mutation rate, lack of pathognomonic findings, and wide overlap with other conditions [15]. Therefore, Faguer et al. [15] developed a $H N F 1 B$ score as a pivotal clinical tool to provide a more rational approach to selecting patients for HNF1B screening. The score can be calculated based on 17 items, including antenatal discovery, family history, and organ involvement (kidneys, pancreas, liver, and genital tract). The authors suggested a score $\geq 8$ as a discriminator between mutation-positive and mutation-negative patients (sensitivity $98.2 \%$, specificity $41.1 \%$, and negative predictive value over 99\%) [15]. In a Japanese study, four out of 33 patients $(12 \%)$ with $H N F 1 B$ mutations had a score $<8$ [7]. A UK study validated the clinical utility of this score in a large number of referrals for $H N F 1 B$ genetic testing and obtained a negative predictive value of $85 \%$ by applying a cutoff score of $\geq 8$ [23]. In a follow-up UK study, HNF1B scores were recalculated after adjustment for the latest available magnesium concentration, and the percentage of patients with a score $\geq 8$ increased to more than $90 \%$ in the older age group [11]. In our study, two patients $(14 \%)$ at onset and one patient $(7 \%)$ at the time of genetic diagnosis had a HNF1B score $<8$ and would have been not eligible for genetic testing when a cutoff score of $\geq 8$ was applied. These findings suggest that the application of the score in younger children may wrongly predict the absence of a mutation because of later development of electrolyte imbalances as well as a lack of renal 
pathological findings and imaging findings of the pancreas and genital tract. Therefore, a revised scoring system or lowering of the cutoff score may be required for younger pediatric patients.

It is known that there are no clear genotype-phenotype correlations in patients with $H N F 1 B$ mutations, which is consistent with consideration of haploinsufficiency as the disease mechanism [3]. However, some studies have shown more favorable renal functional outcomes in patients with gene deletion compared to those in patients with intragenic mutations in $H N F 1 B[7,22]$. Possible explanations for these findings include a dominant negative effect of non-deletion mutations or the involvement of other genes located in the deletion interval on the chromosome locus 17q12.3 [25]. Our study showed no correlation between genotype and renal functional outcomes but higher frequencies of pancreatic abnormalities in patients with missense mutations. However, we cannot generalize these findings with small numbers of our patients with HNF1B mutations. One study found a higher frequency of hypomagnesemia in patients with gene deletion [7]. Another study revealed roughly similar prevalence of hypokalemia and hypomagnesemia in patients with gene deletion and other mutations [13]. Interestingly, neurodevelopmental abnormalities, such as autism and developmental delays, have been reported to be associated with HNF1B mutations, but these complications appear to be restricted to patients with the $17 \mathrm{q} 12$ deletion $[3,4,7,13,25]$. The deleted stretch of DNA contains 14 other genes in addition to HNF1B; therefore, the genetic mechanism underlying these observed neurodevelopmental phenotypes is not clear [3]. However, three patients (21\%) in our study had neurological deficits, but only one had a deletion mutation. Similarly, Faguer et al. [13] reported that mild but obvious mental retardation was recognized in three patients, including two with missense mutations. In other studies, a few patients with intellectual disabilities and intragenic HNF1B mutations have been mentioned [25,28].

\section{Conclusions}

In this study of pediatric patients with $H N F 1 B$ mutations, most patients displayed a slowly progressive course of kidney dysfunction. Genotype did not correlate with renal functional outcomes. However, pancreatic abnormalities were more frequent in patients with missense mutations than in patients with other types of mutations. Neurological deficits were not restricted to patients with total gene deletion. Diagnosis of HNF1B mutations is clinically difficult because of extreme phenotypic variability, incomplete penetrance, a high de novo mutation rate, and wide overlap with other conditions. Furthermore, some phenotypes develop with age. Therefore, patient age should be taken into consideration to increase the diagnostic rate, especially in younger children.

Supplementary Materials: The following are available online at http://www.mdpi.com/2077-0383/9/7/2320/s1, Table S1: Primers used for PCR amplification of the HNF1B gene.

Author Contributions: Conceptualization, S.H.L., J.H.K., Y.H.A., H.G.K., I.-S.H., and H.I.C.; methodology, S.H.L., Y.H.A., and H.I.C.; software, S.H.L.; validation, K.H.H., H.G.K., and I-S.H.; formal analysis, S.H.L., Y.H.A., and H.I.C.; investigation, S.H.L., J.H.K., and K.H.H.; resources, S.H.L., Y.H.A., H.G.K., and H.I.C.; data curation, S.H.L., H.G.K., and H.I.C.; writing-original draft preparation, S.H.L., Y.H.A., and H.I.C.; writing-review and editing, J.H.K., K.H.H., Y.H.A., and H.I.C.; visualization, S.H.L.; supervision, H.G.K., I.-S.H., and H.I.C.; project administration, H.G.K. and H.I.C.; funding acquisition, H.I.C. All authors have read and agreed to the published version of the manuscript.

Funding: This study was supported by a grant from the Korea Health Technology Research \& Development Project through the Korea Health Industry Development Institute funded by the Ministry of Health \& Welfare, Republic of Korea (grant number: HI18C0013).

Conflicts of Interest: The authors declare no conflict of interest.

\section{References}

1. Bach, I.; Mattei, M.G.; Cereghini, S.; Yaniv, M. Two members of an HNF1 homeoprotein family are expressed in human liver. Nucleic Acids Res. 1991, 19, 3553-3559. [CrossRef] [PubMed]

2. El-Khairi, R.; Vallier, L. The role of hepatocyte nuclear factor 1beta in disease and development. Diabetes Obes. Metab. 2016, 18 (Suppl. S1), 23-32. [CrossRef] 
3. Clissold, R.L.; Hamilton, A.J.; Hattersley, A.T.; Ellard, S.; Bingham, C. HNF1B-associated renal and extra-renal disease-an expanding clinical spectrum. Nat. Rev. Nephrol. 2015, 11, 102-112. [CrossRef] [PubMed]

4. Bockenhauer, D.; Jaureguiberry, G. HNF1B-associated clinical phenotypes: The kidney and beyond. Pediatr. Nephrol. 2016, 31, 707-714. [CrossRef] [PubMed]

5. Heidet, L.; Decramer, S.; Pawtowski, A.; Moriniere, V.; Bandin, F.; Knebelmann, B.; Lebre, A.S.; Faguer, S.; Guigonis, V.; Antignac, C.; et al. Spectrum of HNF1B mutations in a large cohort of patients who harbor renal diseases. Clin. J. Am. Soc. Nephrol. 2010, 5, 1079-1090. [CrossRef] [PubMed]

6. Decramer, S.; Parant, O.; Beaufils, S.; Clauin, S.; Guillou, C.; Kessler, S.; Aziza, J.; Bandin, F.; Schanstra, J.P.; Bellanne-Chantelot, C. Anomalies of the TCF2 gene are the main cause of fetal bilateral hyperechogenic kidneys. J. Am. Soc. Nephrol. 2007, 18, 923-933. [CrossRef]

7. Nagano, C.; Morisada, N.; Nozu, K.; Kamei, K.; Tanaka, R.; Kanda, S.; Shiona, S.; Araki, Y.; Ohara, S.; Matsumura, C.; et al. Clinical characteristics of HNF1B-related disorders in a Japanese population. Clin. Exp. Nephrol. 2019, 23, 1119-1129. [CrossRef]

8. Madariaga, L.; Garcia-Castano, A.; Ariceta, G.; Martinez-Salazar, R.; Aguayo, A.; Castano, L.; Spanish group for the study of HNF1B mutations. Variable phenotype in HNF1B mutations: Extrarenal manifestations distinguish affected individuals from the population with congenital anomalies of the kidney and urinary tract. Clin. Kidney J. 2019, 12, 373-379. [CrossRef]

9. Thomas, R.; Sanna-Cherchi, S.; Warady, B.A.; Furth, S.L.; Kaskel, F.J.; Gharavi, A.G. HNF1B and PAX2 mutations are a common cause of renal hypodysplasia in the CKiD cohort. Pediatr. Nephrol. 2011, 26, 897-903. [CrossRef]

10. Raaijmakers, A.; Corveleyn, A.; Devriendt, K.; van Tienoven, T.P.; Allegaert, K.; van Dyck, M.; van den Heuvel, L.; Kuypers, D.; Claes, K.; Mekahli, D.; et al. Criteria for HNF1B analysis in patients with congenital abnormalities of kidney and urinary tract. Nephrol. Dial. Transplant 2015, 30, 835-842. [CrossRef]

11. Adalat, S.; Hayes, W.N.; Bryant, W.A.; Booth, J.; Woolf, A.S.; Kleta, R.; Subtil, S.; Clissold, R.; Colclough, K.; Ellard, S.; et al. HNF1B mutations are associated with a gitelman-like tubulopathy that develops during childhood. Kidney Int. Rep. 2019, 4, 1304-1311. [CrossRef] [PubMed]

12. Bingham, C.; Bulman, M.P.; Ellard, S.; Allen, L.I.; Lipkin, G.W.; Hoff, W.G.; Woolf, A.S.; Rizzoni, G.; Novelli, G.; Nicholls, A.J.; et al. Mutations in the hepatocyte nuclear factor-1beta gene are associated with familial hypoplastic glomerulocystic kidney disease. Am. J. Hum. Genet. 2001, 68, 219-224. [CrossRef] [PubMed]

13. Faguer, S.; Decramer, S.; Chassaing, N.; Bellanne-Chantelot, C.; Calvas, P.; Beaufils, S.; Bessenay, L.; Lengele, J.P.; Dahan, K.; Ronco, P.; et al. Diagnosis, management, and prognosis of HNF1B nephropathy in adulthood. Kidney Int. 2011, 80, 768-776. [CrossRef]

14. Rasmussen, M.; Ramsing, M.; Petersen, O.B.; Vogel, I.; Sunde, L. A description of a fetal syndrome associated with HNF1B mutation and a wide intrafamilial disease variability. Am. J. Med. Genet. A. 2013, 161A, 3191-3195. [CrossRef] [PubMed]

15. Faguer, S.; Chassaing, N.; Bandin, F.; Prouheze, C.; Garnier, A.; Casemayou, A.; Huart, A.; Schanstra, J.P.; Calvas, P.; Decramer, S.; et al. The HNF1B score is a simple tool to select patients for HNF1B gene analysis. Kidney Int. 2014, 86, 1007-1015. [CrossRef]

16. Schwartz, G.J.; Munoz, A.; Schneider, M.F.; Mak, R.H.; Kaskel, F.; Warady, B.A.; Furth, S.L. New equations to estimate GFR in children with CKD. J. Am. Soc. Nephrol. 2009, 20, 629-637. [CrossRef]

17. Levey, A.S.; Stevens, L.A.; Schmid, C.H.; Zhang, Y.L.; Castro, A.F., 3rd; Feldman, H.I.; Kusek, J.W.; Eggers, P.; van Lente, F.; Greene, T.; et al. A new equation to estimate glomerular filtration rate. Ann. Intern. Med. 2009, 150, 604-612. [CrossRef]

18. Ahn, Y.H.; Lee, C.; Kim, N.K.D.; Park, E.; Kang, H.G.; Ha, I.S.; Park, W.Y.; Cheong, H.I. Targeted exome sequencing provided comprehensive genetic diagnosis of congenital anomalies of the kidney and urinary tract. J. Clin. Med. 2020, 9, 751. [CrossRef]

19. Kang, H.G.; Lee, M.; Lee, K.B.; Hughes, M.; Kwon, B.S.; Lee, S.; McNagny, K.M.; Ahn, Y.H.; Ko, J.M.; Ha, I.S.; et al. Loss of podocalyxin causes a novel syndromic type of congenital nephrotic syndrome. Exp. Mol. Med. 2017, 49, e414. [CrossRef]

20. Richards, S.; Aziz, N.; Bale, S.; Bick, D.; Das, S.; Gastier-Foster, J.; Grody, W.W.; Hegde, M.; Lyon, E.; Spector, E.; et al. Standards and guidelines for the interpretation of sequence variants: A joint consensus recommendation of the American college of medical genetics and genomics and the association for molecular pathology. Genet. Med. 2015, 17, 405-424. [CrossRef] 
21. Mefford, H.C.; Clauin, S.; Sharp, A.J.; Moller, R.S.; Ullmann, R.; Kapur, R.; Pinkel, D.; Cooper, G.M.; Ventura, M.; Ropers, H.H.; et al. Recurrent reciprocal genomic rearrangements of 17q12 are associated with renal disease, diabetes, and epilepsy. Am. J. Hum. Genet. 2007, 81, 1057-1069. [CrossRef] [PubMed]

22. Dubois-Laforgue, D.; Cornu, E.; Saint-Martin, C.; Coste, J.; Bellanne-Chantelot, C.; Timsit, J.; Monogenic Diabetes Study Group of the Société Francophone du Diabète. Diabetes, associated clinical spectrum, long-term prognosis, and genotype/phenotype correlations in 201 adult patients with hepatocyte nuclear factor 1B (HNF1B) molecular defects. Diabetes Care 2017, 40, 1436-1443. [CrossRef] [PubMed]

23. Clissold, R.; Shields, B.; Ellard, S.; Hattersley, A.; Bingham, C. Assessment of the HNF1B score as a tool to select patients for HNF1B genetic testing. Nephron 2015, 130, 134-140. [CrossRef]

24. Ferre, S.; Veenstra, G.J.; Bouwmeester, R.; Hoenderop, J.G.; Bindels, R.J. HNF-1B specifically regulates the transcription of the gammaa-subunit of the Na+/K+-ATPase. Biochem. Biophys Res. Commun. 2011, 404, 284-290. [CrossRef] [PubMed]

25. Okorn, C.; Goertz, A.; Vester, U.; Beck, B.B.; Bergmann, C.; Habbig, S.; Konig, J.; Konrad, M.; Muller, D.; Oh, J.; et al. HNF1B nephropathy has a slow-progressive phenotype in childhood-with the exception of very early onset cases: Results of the German multicenter HNF1B childhood registry. Pediatr. Nephrol. 2019, 34, 1065-1075. [CrossRef]

26. Adalat, S.; Woolf, A.S.; Johnstone, K.A.; Wirsing, A.; Harries, L.W.; Long, D.A.; Hennekam, R.C.; Ledermann, S.E.; Rees, L.; van't Hoff, W.; et al. HNF1B mutations associate with hypomagnesemia and renal magnesium wasting. J. Am. Soc. Nephrol. 2009, 20, 1123-1131. [CrossRef]

27. Kanda, S.; Morisada, N.; Kaneko, N.; Yabuuchi, T.; Nawashiro, Y.; Tada, N.; Nishiyama, K.; Miyai, T.; Sugawara, N.; Ishizuka, K.; et al. New-onset diabetes after renal transplantation in a patient with a novel HNF1B mutation. Pediatr. Transplant 2016, 20, 467-471. [CrossRef]

28. Dubois-Laforgue, D.; Bellanne-Chantelot, C.; Charles, P.; Jacquette, A.; Larger, E.; Ciangura, C.; Saint-Martin, C.; Rastel, C.; Keren, B.; Timsit, J.; et al. Intellectual disability in patients with MODY due to hepatocyte nuclear factor 1B (HNF1B) molecular defects. Diabetes Metab. 2017, 43, 89-92. [CrossRef]

(C) 2020 by the authors. Licensee MDPI, Basel, Switzerland. This article is an open access article distributed under the terms and conditions of the Creative Commons Attribution (CC BY) license (http://creativecommons.org/licenses/by/4.0/). 